\title{
PLGA-corosolic acid implants for potential application in ocular neovascularization diseases
}

\author{
Cibele Rodrigues Toledo ${ }^{1}$, Vinícius Viana Pereira ${ }^{\circledR 1}$, \\ Gracielle Ferreira Andrade ${ }^{2}$, Armando Silva-Cunha ${ }^{1}$ \\ ${ }^{I}$ Department of Pharmaceutical Products, Faculty of Pharmacy, Federal University \\ of Minas Gerais, Belo Horizonte, Minas Gerais, Brazil, ${ }^{2}$ Center of Development \\ of the Nuclear Technology (CDTN), Belo Horizonte, Minas Gerais, Brazil
}

\begin{abstract}
Angiogenesis is the formation of new blood vessels from preexisting vasculature. Uncontrolled angiogenesis is associated with progression of several ocular pathologies, such as diabetic retinopathy and macular degeneration. Thus, the inhibition of this process consists in an interesting therapeutic target. Corosolic acid (CA) is a natural derivative of ursolic acid, found in many medicinal herbs and exhibits numerous biological properties, including the antiangiogenic activity. The present study reports the production of CA-loaded poly d,l-lactidecoglycolide acid (PLGA) devices by melt technique. HPLC-UV method was developed and validated to evaluate the uniformity and the release profile of the developed systems. The devices were also characterized by Fourier transform infrared spectroscopy, thermal analysis, and scanning electron morphology. It was studied the antiangiogenic activity of the CA-polymer system, using an in vivo model, the chorioallantoic membrane assay (CAM). CA was dispersed uniformly in the polymer matrix and no chemical interaction between the components of the formulation was verified. The implants presented a sustained release of the drug, which was confirmed by the morphological study and demonstrated an antiangiogenic activity. Therefore, the developed delivery system is a promising therapeutic tool for the treatment of ocular diseases associated with neovascularization or others related to the angiogenic process.
\end{abstract}

Keywords: Corosolic acid. PLGA. Antiangiogenic activity. Implant.

\section{INTRODUCTION}

Angiogenesis or neovascularization is a natural process responsible for the formation of new blood vessels from preexisting vasculature (Elshabrawy et al., 2015). The neovascularization is controlled by several molecules that stimulate (pro-angiogenic) and inhibit (antiangiogenic) the formation of new blood vessels (Gacche, Meshram, 2014). In normal physiological conditions, there is a dynamic balance between proangiogenic and antiangiogenic factors. However, in pathological circumstances, the balance between these factors is lost by some chemical, mechanical,

*Correspondence: Cibele Toledo, Universidade Federal de Minas Gerais, UFMG, Faculty of Pharmacy. Av. Antônio Carlos, 6627, Pampulha, Belo Horizonte, Minas Gerais. Tel.: +55 (31) 31270-901, Brazil. E-mail: ci.toledo02@gmail.com degenerative or infectious stimulus, resulting in hyperstimulation of pro-angiogenic factors which leads to an uncontrolled cell multiplication and formation of functionally and structurally disordered neovessels (Behl, Kotwani, 2015).

Among the factors involved in angiogenesis, vascular endothelial growth factor (VEGF) is one of the most important pro-angiogenic factors, due to its vascular endothelium specificity and its ability to induce vasodilation via $\mathrm{NO}$ endothelial production. Under hypoxic conditions, VEGF is excessively produced, resulting in dysregulated angiogenesis that plays an important role in the progression of several pathologies, such as proliferative diseases of retina, chronic inflammation, rheumatoid arthritis, psoriasis, endometriosis, tumor growth and metastasis (Kanjoormana, Kuttan 2010; Katrancioglu et al., 
2012). Therefore, the inhibition of this process may be an interesting therapeutic target, especially for the treatment of ocular neovascularization diseases. New drugs are still be sought to antiangiogenic therapy and, based on this, plant-derived compounds comprise potential pharmacological agents (Balakrishnan, Al Assaf, 2016).

Pentacyclic triterpenes are secondary metabolites widely distributed in the plant kingdom, which are commonly object of pharmacological and phytochemical research (Nazaruk, Borzym-Kluczyk, 2014). According to their skeleton, they are divided into some groups, of which the ursanes and oleanes are the most common structures (Alvarado et al. 2015b). Representatives of those, such as ursolic acid, maslinic acid and oleanolic acid were previously reported to have antiangiogenic properties (Hussain et al., 2012; Kanjoormana, Kuttan, 2010; Kashyap et al., 2018; Thakor et al., 2017; Zhu et al., 2013). In this research, we focus on one of the triterpenes, corosolic acid $\left(\mathrm{CA} ; \mathrm{C}_{30} \mathrm{H}_{48} \mathrm{O}_{4}\right.$; molar mass 472.71 g. $\left.\mathrm{mol}^{-1}\right)$. CA ( $2 \alpha$-hydroxyursolic acid) is a natural derivative of ursolic acid, that can be found in many medicinal herbs such as: Lagerstroemia speciosa (banaba) (Yang et al., 2016), Ugni molinae (murtilla) (Arancibia-Radich et al., 2016), Eriobotrya japonica (loquat) (Tan, Sonam, Shimizu, 2017) and Jacaranda oxyphylla Cham. ("caroba-de-São-Paulo") (Pereira et al., 2016).

It has been reported that CA exhibits numerous biological properties, including antidiabetic (Nazaruk, Borzym-Kluczyk, 2014; Yang et al., 2016), antioxidative (Li et al., 2016), anti-tumoral (Cheng et al., 2017), antiseptic and anti-aging (Tan et al., 2017) activities. Recently, it was demonstrated that CA also presents antiangiogenic activity (Ku et al., 2015; Yoo et al., 2015). $\mathrm{Ku}$ and collaborators have demonstrated that $\mathrm{CA}$ is able to block the ATP binding site, resulting in inhibition of VEGFR2 kinase activity, which is a major receptor that participates in the angiogenesis process (Ku et al., 2015).

Currently, there is a compelling need for the development of biodegradable ophthalmic polymeric system for controlled and local release. This kind of technology offers some advantages, such as the availability of the drug directly at the site of action, reduction of adverse systemic effects and administration frequency, meaning improvement in patient compliance, safety and efficacy (Patel et al., 2013; Ma et al., 2017). PLGA (poly d,l-lactidecoglycolide acid), a biodegradable and biocompatible polymer, approved by the Food and
Drug Administration (FDA) and the European Medicine Agency (EMA), is the main used carrier for sustained drug delivery.

Implantable polymeric drug delivery systems have been proposed for ocular applications and some medicines have been approved by the FDA, for example, Ozurdex ${ }^{\circledR}$ and Iluvien ${ }^{\circledR}$. In addition, there is no report of non-steroidal drugs approved by the FDA for the treatment of pathologies associated with angiogenesis, what justifies this study. Furthermore, it has been reported the success of the association between PLGA and triterpenes in terms of incorporation and efficacy (Alvarado et al., 2015a; Soares et al., 2017). However, at present, no study has designed a PLGA device to vehiculize CA in a sustained release system for angiogenic pathologies. Based on this, this work aimed to develop and evaluate the antiangiogenic activity of CA-loaded PLGA implant, envisioning its application in the treatment of ocular diseases associated with neovascularization.

\section{MATERIAL AND METHODS}

\section{Chemical and reagents}

Poly (D, L-lactide-coglycolide) in ratio of 50:50 [PLGA (50:50)] was purchased from Boehringer Ingelheim (Germany). Corosolic acid (MW 472.71, obtained from Jacaranda oxyohylla) was offered by the Center of Studies and Research in Medicinal Plants of Chemistry Department of UFMG (Belo Horizonte, Brazil) and the corosolic acid chemical reference substance was purchased from Sigma Aldrich (USA) (MW 472.71, purity $\geq 98 \%$ ). Ultrapure water was produced by a Milli-Q ${ }^{\circledR}$ purification system (Millipore, USA). Methanol was purchased from Merck (Brazil). The other solvents and reagents used were of analytical grade.

\section{PLGA-CA implant preparation}

Implants were prepared by the hot molding technique according to the procedure described by Fialho and Silva-Cunha (2007). The PLGA 50:50 implants were loaded with $15 \%$ (w/w) of CA (Yasukawa et al., 2005). Firstly, CA and PLGA were dissolved in 90 $\mu \mathrm{L}$ of DMSO and an appropriate quantity of acetonitrile as the organic solvent. This suspension was lyophilized. The obtained powder was molded into rods using a 
Teflon ${ }^{\circledR}$ sheet heated at the temperature of $100-120{ }^{\circ} \mathrm{C}$. The mean weight of the implants was $1.21 \pm 0.06 \mathrm{mg}$.

\section{Development of chromatographic method}

HPLC-UV analyses were carried out on an Agilent ${ }^{\circledR}$ 1260 Infinity System (USA) using the analytical column LiChrosorb ${ }^{\circledR} \mathrm{RP}-18,250$ x $4.6 \mathrm{~mm} ; 5 \mu \mathrm{m}$ (Merck, Brazil). The compound was detected at a wavelength of

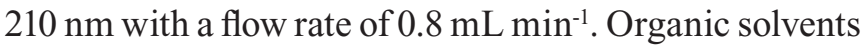
such as acetonitrile, methanol, and aqueous phases as water, phosphate acid $0.1 \%$ and formic acid $0.1 \%$ were tested at different rates to select the best mobile phase. Finally, the mobile phase methanol: water: formic acid $(88: 12: 0.1 \mathrm{v} / \mathrm{v} / \mathrm{v}, \mathrm{pH}=6.8)$ was chosen because offered the best peak shape. The injection volume was $20 \mu \mathrm{L}$. All determinations were performed at $40{ }^{\circ} \mathrm{C}$ under isocratic elution. The retention time observed for the samples was about 11 minutes.

\section{Preparation of solutions}

\section{Standard solution}

$5 \mathrm{mg}$ of CA reference standard were accurately weighed and transferred to a $5 \mathrm{~mL}$ volumetric flask and dissolved in methanol to obtain a final concentration of 1 $\mathrm{mg} \mathrm{mL}{ }^{-1}$. All the standard solutions were filtered through $0.45 \mu \mathrm{m}$ filter (Sartorius, Germany). The concentration of $\mathrm{CA}$ in each solution prepared was defined in the description of the validation parameter.

\section{Placebo solution}

The implant of PLGA (without drug) was transferred to a $1 \mathrm{~mL}$ volumetric flask. One drop of acetonitrile was added to ensure complete solubilization, and the volume was adjusted with methanol. The placebo solution was filtered through $0.45 \mu \mathrm{m}$ filter (Sartorius, Germany).

\section{Analytical method validation}

Validation of the developed method was carried out as preconized by the International Conference on Harmonization Guidelines for validation of analytical procedures (International Conference on Harmonisation, 2005). It included the evaluation of selectivity, calibration curve, precision, accuracy, robustness, detection and quantitation limits (LOD and LOQ).
Selectivity was confirmed by comparing the chromatographic peaks of CA reference-standard, blank samples of methanol, mobile phase and PLGA solution. To achieve selectivity of the method, no peak with the same retention time of CA is allowed.

Linearity was evaluated by constructing the calibration curves at six concentration levels in the range of $50-300 \mu \mathrm{g} \mathrm{mL}^{-1}$ for CA standard solution in three independent experiments. The calibration curves constructed were assessed using residue analysis (homoscedasticity, normality and independence of residues) and the linear regression was done by the weighted least squares method. The correlation coefficient was calculated. The limit of detection (LOD) and limit of quantification (LOQ) were calculated from the calibration curve, considering the residual standard deviation of regression line.

Precision was determined based on repeatability (intra-assay) and intermediate precision (inter-assay). Repeatability was performed through the assay of three solutions $\left(100,200\right.$ e $\left.300 \mu \mathrm{g} \mathrm{mL}^{-1}\right)$ on the same day. Intermediate precision was verified by evaluating the results in two consecutive days. The solutions were prepared in triplicate.

Recovery test was carried out to determine the accuracy. For this, three solutions (100, 200 e $300 \mu \mathrm{g} \mathrm{ml}$ $\left.{ }^{1}\right)$ were prepared in triplicate by the incorporation of CA standard in placebo solution.

Robustness was studied by determining the effects of small variations of mobile phase composition, the flow rate and temperature.

\section{Determination of CA content in the polymeric-systems}

Immediately after the production, an amount of ten biodegradable CA-loaded PLGA implants were weighted and transferred to a $1 \mathrm{ml}$ volumetric flask. One drop of acetonitrile was added to ensure complete solubilization, and the volume was adjusted with methanol. All the sample solutions were filtered through $0.45 \mu \mathrm{m}$ filter (Sartorius, Germany). The amount of CA was determined by high performance liquid chromatography method described above. The CA concentration was calculated by the area under the curve and the results were expressed as the percentage content of the pre-indicated value (15.0\%). 


\section{Physicochemical characterization}

\section{Fourier transform infrared spectroscopy (FTIR)}

The FTIR spectra of the samples constituted by CA; PLGA and CA loaded PLGA implants were recorded on the Frontier Single Ranger (MIR) Spectrometer (Perkin-Elmer) and measurements were carried out using the Attenuated Total Reflectance (ATR) technique, in the range of $4000-550 \mathrm{~cm}^{-1}$, of 16 scans and a resolution of $4 \mathrm{~cm}^{-1}$.

\section{Thermal analysis}

Thermal behavior of the samples was analyzed by thermogravimetry (TG) and differential scanning calorimetry (DSC) using a DSC-50 (Shimadzu). The samples constituted by CA; PLGA; a physical mixture of CA and PLGA and CA loaded PLGA implants were heated in semi-hermetic aluminum pans from $25{ }^{\circ} \mathrm{C}$ to $300{ }^{\circ} \mathrm{C}$ $\left(10{ }^{\circ} \mathrm{C} \mathrm{min}{ }^{-1}\right)$ under nitrogen atmosphere $\left(50 \mathrm{ml} \mathrm{min}^{-1}\right)$.

\section{Morphological characterization}

The structure of CA-loaded PLGA implants was examined morphologically using a Scanning Electron Microscope (JEOL JSM6360LV) operating at $15 \mathrm{kV}$. All micrographs were obtained from the fracture surfaces coated with gold. The surfaces of the implants were observed at $100-5000$ magnification.

\section{In vitro CA release study}

In vitro release of CA from CA-loaded PLGA implants was carried out in triplicate in the release medium (PBS buffer, $\mathrm{pH}$ 7.4). Each implant, previously weighted, was immersed in $4 \mathrm{ml}$ of PBS in a closed flask. These flasks were kept inside an incubator (TECNAL, model TE-424) set at $37^{\circ} \mathrm{C}$ and $30 \mathrm{rpm}$. Along 54 days, at predetermined intervals (weeks 1, 2, 4, 6 and 8) three implants were taken out.

In order to evaluate water absorption by the implants and weight loss, the implants were weighed immediately and 72 hours after the collection. The weight variation was calculated by the following equation and expressed as a percentage.

$\Delta$ weight $(\%)=100 \times($ wo-wf $) /$ wo
Where wo is the initial weight and wf is the weight after the release study.

Then, the implants were quantified by HPLCUV method previously described and expressed as the weekly and cumulative percentage of CA released in the medium, calculated by:

CA released $(\%)=100 \times($ Qo-Qf $) /$ wo

Where Qo is the initial amount of CA and Qf is the amount of CA in implant after the release study.

\section{In vivo antiangiogenic study}

In order to investigate the antiangiogenic activity, CA-loaded PLGA implants in $15 \%(\mathrm{w} / \mathrm{w})$ were applied in the chorioallantoic membrane (CAM) assay. For this purpose, 50 freshly fertilized eggs (Gallus domesticus) were previously incubated for 72 hours at $37{ }^{\circ} \mathrm{C}$ and relative air humidity of $60 \%$. Then, a circular hole of approximately $1 \mathrm{~cm}$ of diameter was made in the eggshell air chamber. The inner shell membrane was removed to expose the CAM (day 3). The windows in the eggshell were covered with an adhesive tape and thereafter, the eggs were incubated for more 48 hours. Subsequently, on the $5^{\text {th }}$ day, the tapes were removed and the samples were applied over the CAM in a predetermined site. The tapes were placed again and the eggs were incubated for more 48 hours. On the $7^{\text {th }}$ day of embryo development, CAMs were fixed with a formaldehyde solution $10 \%$ during 10 minutes. Then, the membranes were extracted and analyzed with a stereomicroscope (Motic ( $\mathrm{B}$ SMZ168) coupled to a digital camera (Motic cam). For CAM vasculature evaluation, the obtained images were converted to the grayscale using ImageJ software (version 1.50i National Institutes of Health, USA) and the negative control group was set to $100 \%$ for blood vessels quantification.

The samples applied to the CAMs were PBS buffer $\mathrm{pH} 7.4(50 \mu \mathrm{L})$ as the negative control; bevacizumab solution at $250 \mu \mathrm{g} \mathrm{ml}^{-1}(50 \mu \mathrm{L})$ as the positive control; PLGA blank implants; CA-loaded PLGA implants and CA suspension at $250 \mu \mathrm{g} \mathrm{ml}^{-1}(50 \mu \mathrm{L})$.

The concentration of CA suspension was based on CA daily release from the implants obtained during the in vitro study. Therefore, this concentration was calculated considering a linear release of CA during 60 hours. 


\section{Statistical analysis}

Statistical evaluation of the data was performed using one-way analysis of variance (ANOVA) followed by post-test of Tukey to compare the significance between the different groups, using the software GraphPad Prism®5. A p-value $<0.05$ was considered statistically significant.

\section{RESULTS AND DISCUSSION}

\section{Analytical method validation}

HPLC-UV method was developed and validated for quantitative determination of CA content incorporated into polymeric systems and released from these devices.

Representative chromatographic profile of $\mathrm{CA}$ in the presence of possible interferes is shown in Figure 1. Any interfering peaks were observed at the retention time of CA (11.4 minutes) and thus, the method was considered specific.

A great linearity was obtained over a concentration range of $50-300 \mu \mathrm{g} \mathrm{mL} \mathrm{m}^{-1}$. The calibration curve could be defined by the following equation: $y=1465752.5268 x$ - 3892851.8889, where $y$ attends for the area under the curve and $\mathrm{x}$ the concentration $\left(\mu \mathrm{g} \cdot \mathrm{mL}^{-1}\right)$. The correlation coefficient of the obtained curve was 0.9993 , indicating a highly significant correlation between concentration and peak area. Through the weighted least square method, the linear model proved to be adequate since the residues followed a normal distribution pattern, were independent and homoscedastic. In addition, the lack of fit was not significant.

The LOD and LOQ were estimated to check the sensitivity of the method. The signal-to-noise ratio for LOD was considered as 3:1 and 10:1 for LOQ. The LOD and LOQ were found to be 0.91 and $2.75 \mu \mathrm{g} \mathrm{m}^{-1}$, respectively.

Repeatability and intermediate precision were expressed as the relative standard deviation (RSD). The results obtained are presented in Table I, and the values in both cases were satisfactory, presenting values less than 1.7.

Accuracy was calculated as a percentage of the recovery test and the results are shown in Table I. The recovery values were within the acceptable limits (98 $-102 \%$ ) and the RSD was lower than $2 \%$, proving the accuracy of the developed method.

Moreover, the developed method proved to be robust for temperature changes. The flow rate and mobile phase composition should be carefully controlled since modifications in these parameters could affect the retention time and the symmetry of CA peak.

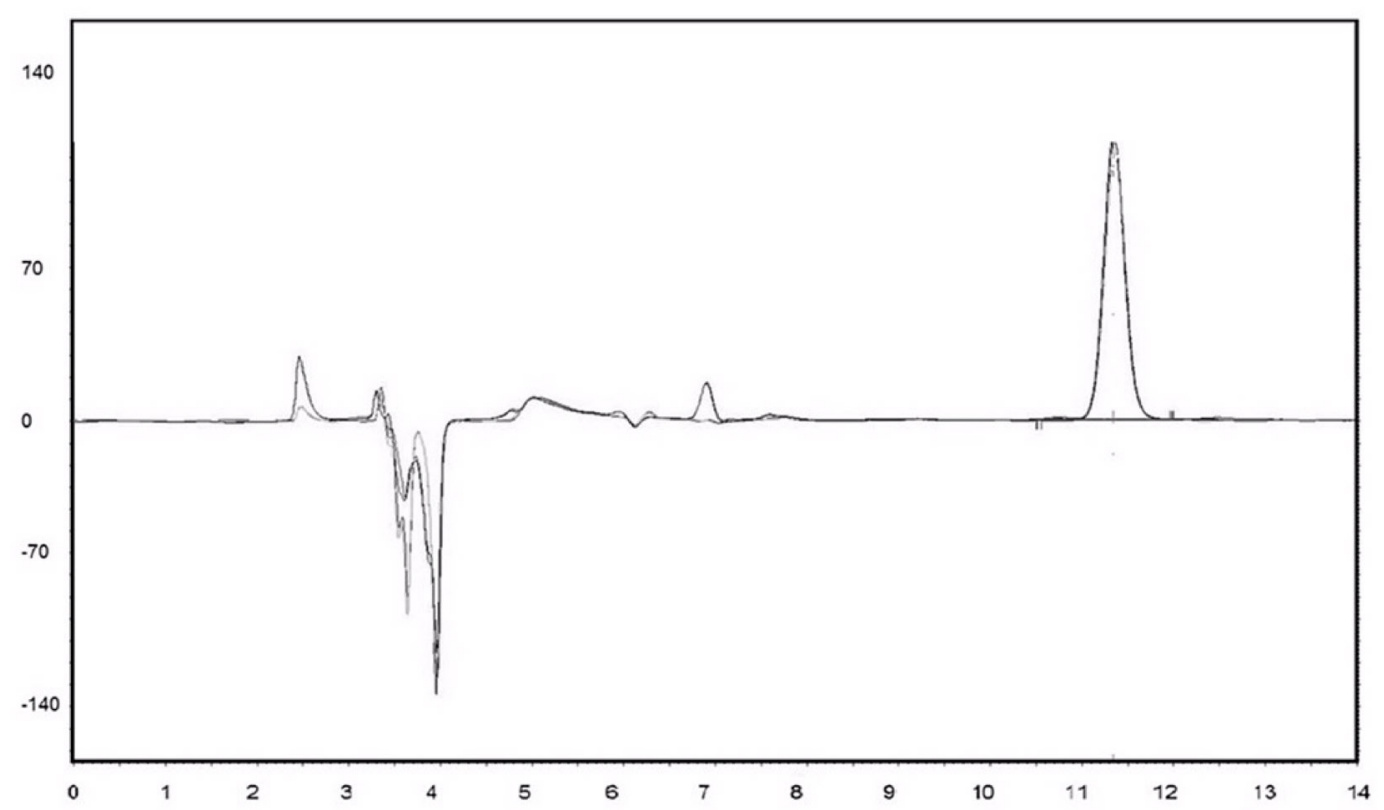

FIGURE 1 - Overlapped chromatograms obtained during selectivity study, under experimental conditions. 
TABLE I - Validation parameters for CA quantification

\section{Precision intra-assay}

\begin{tabular}{|c|c|c|}
\hline Theorical concentration $\left(\mu \mathrm{g} \mathrm{ml}^{-1}\right)$ & Experimental concentration $\left(\mu \mathrm{g} \mathrm{ml}^{-1}\right)$ & RSD \% \\
\hline 100 & 96.43 & 0.26 \\
\hline 200 & 185.37 & 0.08 \\
\hline 300 & 286.78 & 0.05 \\
\hline \multicolumn{3}{|c|}{ Precision inter-assay } \\
\hline 100 & 96.30 & 1.06 \\
\hline 200 & 183.61 & 1.55 \\
\hline 300 & 286.81 & 1.68 \\
\hline \multicolumn{3}{|c|}{ Recovery test } \\
\hline 100 & 100.85 & 1.97 \\
\hline 200 & 98.94 & 0.22 \\
\hline 300 & 101.84 & 0.13 \\
\hline
\end{tabular}

\section{Determination of CA content in the polymeric-systems}

CA content in the developed devices was quantified by the chromatographic method described. The mean of the drug incorporated into polymeric systems was 77.06 $\pm 2.32 \%(\mathrm{n}=10)$ of the pre-indicated value $(15 \% \mathrm{w} / \mathrm{w})$ and CA was dispersed uniformly in the polymeric matrix.

\section{Physicochemical characterization}

\section{Fourier transform infrared spectroscopy (FTIR)}

FTIR technique was applied to investigate the occurrence of possible chemical interactions between $\mathrm{CA}$ and PLGA chains and subsequent modifications in the original molecular structure, which could lead to changes or loss of biological activity. The FTIR spectrum of CA (Figure 2A) showed absorption bands at $3383 \mathrm{~cm}^{-1}$, corresponding to the stretching of $\mathrm{O}-\mathrm{H}$ linkage of alcohol and carboxylic acid, at 2926 and 2864 $\mathrm{cm}^{-1}$, referring to stretching of $\mathrm{C}-\mathrm{H}$ ( $\mathrm{Li}$ et al., 2014). The absorption bands at 1457 and $1377 \mathrm{~cm}^{-1}$ refer to the angular deformation of $\mathrm{C}-\mathrm{H}$ linkage of aliphatic groups. There is also two overlapped bands at 1748 and 1687 $\mathrm{cm}^{-1}$ related, respectively, to $\mathrm{C}=\mathrm{O}$ stretching from acid monomers and aggregated species which means that a great part of CA is in form of dimers or aggregates. Similar results were observed by Lorincz et al. (2015).

FTIR spectrum of blank PLGA 50:50 (Figure 2B) presented a characteristic band at $1759 \mathrm{~cm}^{-1}$, assigned to stretching of ester carbonyl groups $(\mathrm{C}=\mathrm{O})$. Stretching and angular deformations of C-H were observed, respectively, at 2998 and $2951 \mathrm{~cm}^{-1}$ and from 1450 to $1375 \mathrm{~cm}^{-1}$. Similar types of bands were also observed in previous works (Vey et al., 2011; Keles et al., 2014).

Typical absorption bands of the functional groups of CA and PLGA 50:50 were demonstrated in the 
FTIR spectra of the physical mixture (CA+ PLGA) and of CA-loaded PLGA implants (Figure 2C) and no new bands were observed. Thus, the structure of both compounds has remained stable, indicating that no effective chemical bond has been occurred between then (Soares et al., 2017). Moreover, it was evidenced the quality of the manufacturing process, since the presence of absorption bands referred to the solvents employed during the preparation of CA-loaded PLGA implants was not observed.

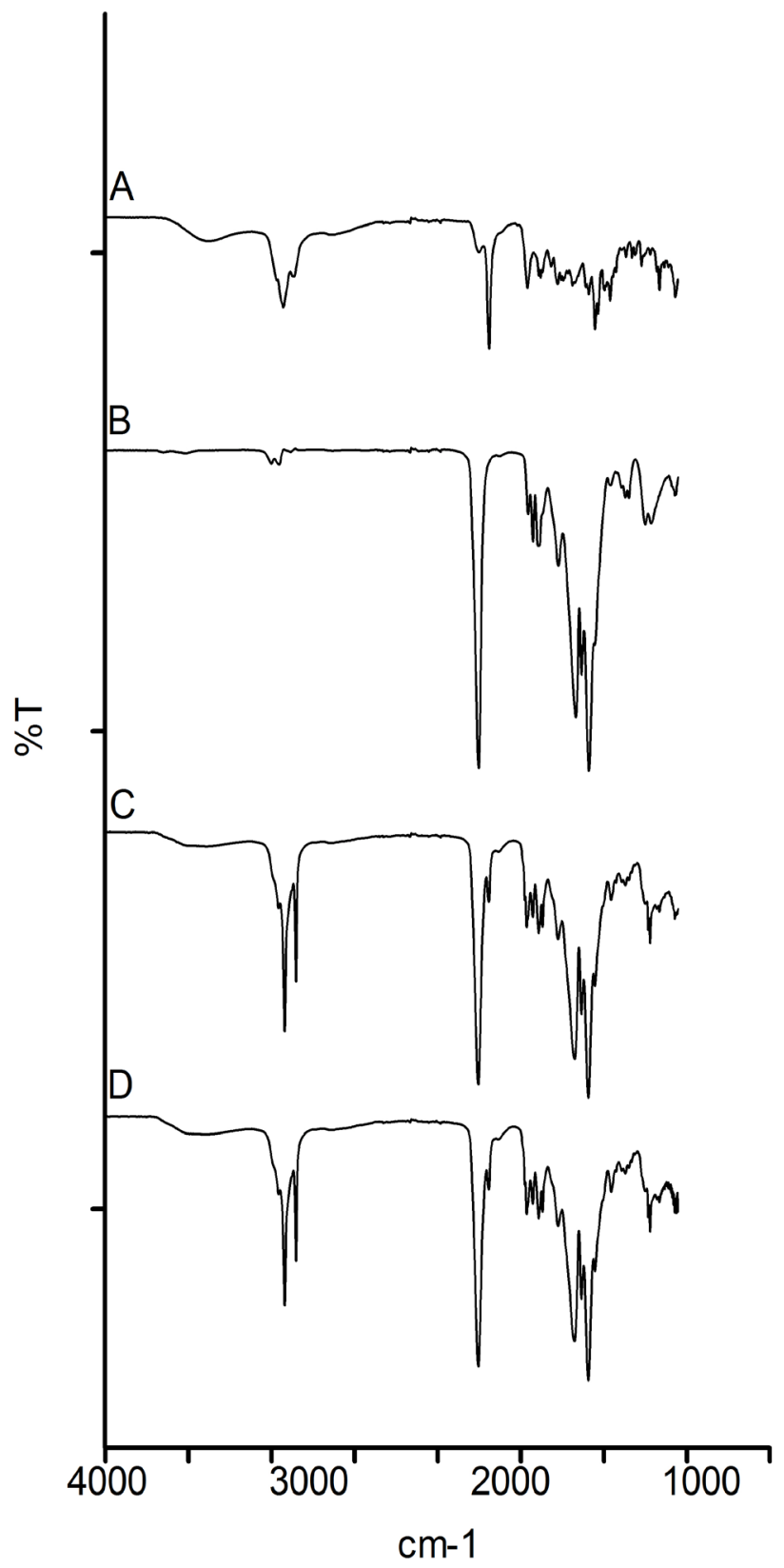

FIGURE 2 - FTIR spectra of CA (A), PLGA (B); physical mixture (C); CA-loaded PLGA implant (D).

\section{Thermal analysis}

Thermal analysis was employed to evaluate the possibility of any physical-chemical interaction between CA and PLGA 50:50 within the polymeric matrix. TG thermogram of CA, PLGA and CAloaded PLGA implants (Figure 3) showed a single well-defined event corresponding to the thermal degradation at temperatures up to $250{ }^{\circ} \mathrm{C}$ (Solano et al., 2013). Only the physical mixture showed two events of degradation, the first referring to PLGA and the second related to CA.

The DSC curve of CA (Figure 4A) showed an endothermic event at $255{ }^{\circ} \mathrm{C}$ ( $\mathrm{T}$ onset at $251{ }^{\circ} \mathrm{C}$ ), attributed to the melting point of this substance (Elmoghazy et al. 2016). PLGA 50:50 (Figure 4B) presented an endothermic reaction at $54{ }^{\circ} \mathrm{C}$ in this DSC curve, which is correlated to the glass transition (Jahangiri et al., 2014; Sun et al., 2015). Due to the amorphous phase of the polymer, events indicating the melting point of PLGA 50:50 was not demonstrated (Soares et al., 2017). DSC curve of the physical mixture presented both endothermic events (at $54^{\circ}$ and $255^{\circ} \mathrm{C}$ ). Finally, the DSC curve of CA-loaded PLGA implant (Figure 4C) showed an endothermic process at $55^{\circ} \mathrm{C}$, referring to the PLGA glass transition. However, the peak of CA at $255{ }^{\circ} \mathrm{C}$ disappeared or diminished considerably, indicating the complete entrapment of CA by the polymer chains (Anwer et al., 2016) or by the drug transition to the amorphous state during the liofilization process (Eloy, Marchetti, 2014). No other significant peak was observed in DSC curves, supporting that no significant chemical changes or interactions occurred between CA and PLGA, as observed in the FTIR analysis. 


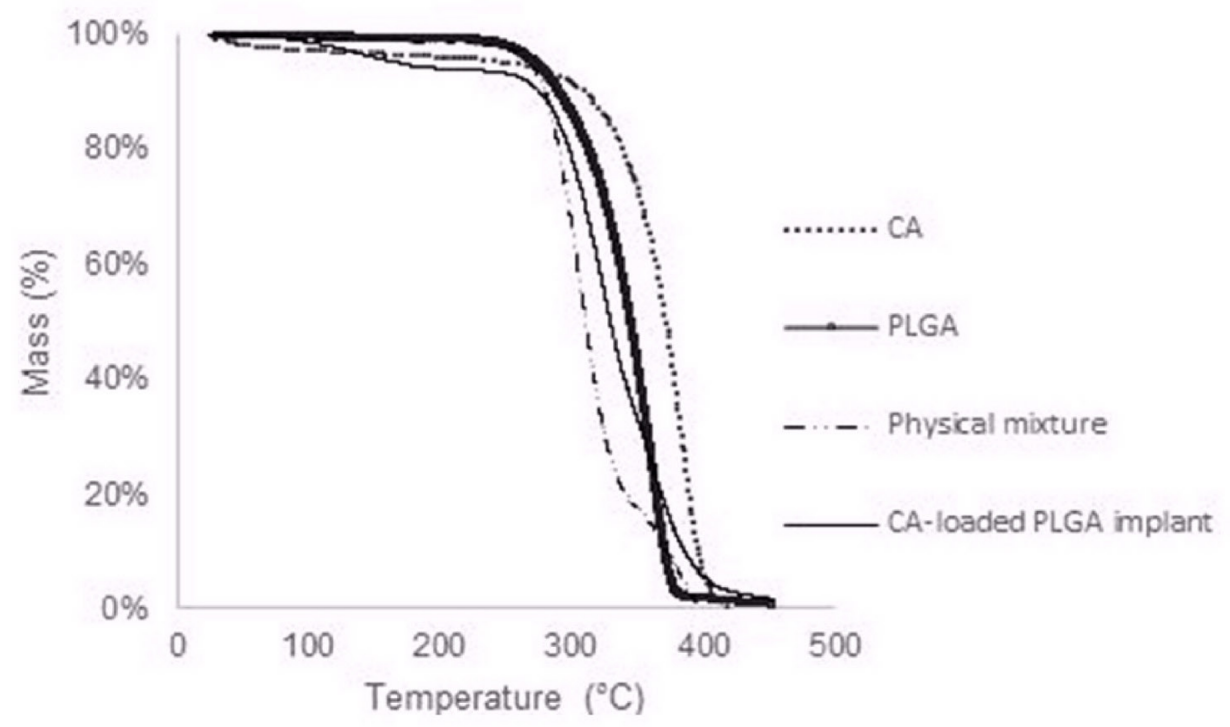

FIGURE 3 - TG curves of CA, PLGA, physical mixture, CA-loaded PLGA implant.

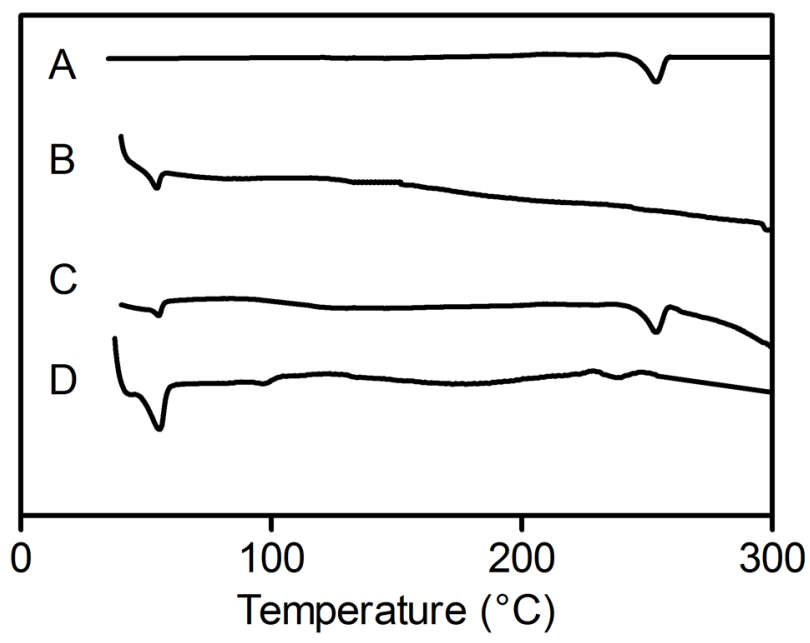

FIGURE 4 - DSC curves of (A) CA; (B) PLGA; (C) physical mixture; (D) CA-loaded PLGA implant.

\section{Morphological characterization}

Morphological study was conducted to investigate the microstructure of CA-loaded implants (Figure 5) in the initial time and after 15 and 30 days of the drug release study. Micrographs revealed a homogeneous and smooth surface with no evidence of pores or channels before the beginning of the drug release test.
However, the surfaces of the implants with 15 and 30 days of release study, was found to be heterogeneous and with a few pores and channels, indicating the process of matrix erosion. In this context, the CA dispersed in the polymer matrix can be released through the pores by diffusion, degradation of the polymer or a combination of the two mechanisms (Boimvaser et al., 2016; Cossé et al., 2017). 

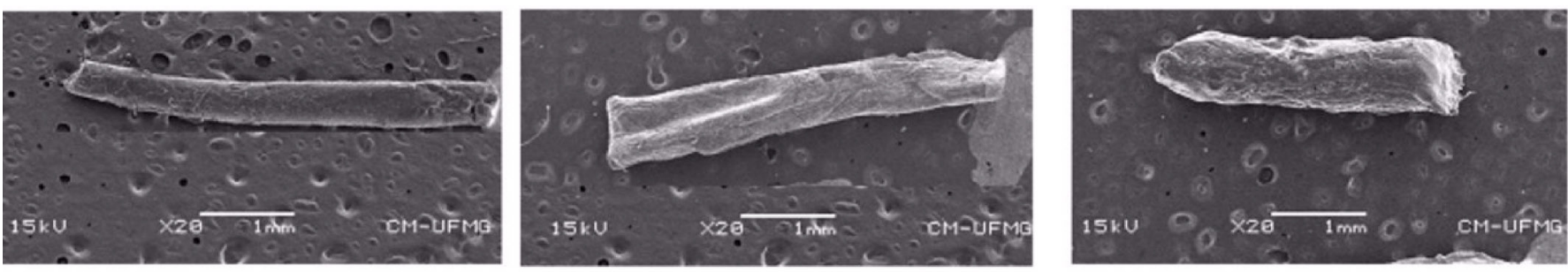

FIGURE 5 - SEM images of the external surface of CA-loaded PLGA implants: (A) before (B) 15 days and (C) 30 days of release study. Magnification of 20x.

\section{In vitro CA release study}

CA release profile from PLGA implants in PBS buffer $\mathrm{pH} 7.4$ is presented in Figure 6A and the erosion profile is shown in Figures 6B-C. A prolonged release of CA over 54 days was observed, characterized by a biphasic profile. In the first stage, there was a low burst release of CA; around $25 \%$ of CA content was released in the week 1 , which could be related to the presence of CA associated to the surface of the polymer matrix. In the second stage, between weeks 2 and 8 , around $60 \%$ of CA was released, with an approximately weekly rate of $10 \%$. During the first four weeks, no relevant weight loss of the implant was shown, which is attributed to the initial phase of PLGA degradation process. During this period, a high water absorption occurred, which promoted ester bonds hydrolysis of the polymer structure (Boimvaser et al., 2016; Cossé et al., 2017), culminating with the appearance of pores in the matrix and, subsequently, the beginning of implant weight loss process. Although there were new channels in the polymer matrix, the CA release to the medium occurred slowly due to the hydrophobic structure of CA, which may contribute to its higher affinity for the matrix and a reduction of the diffusion rate.
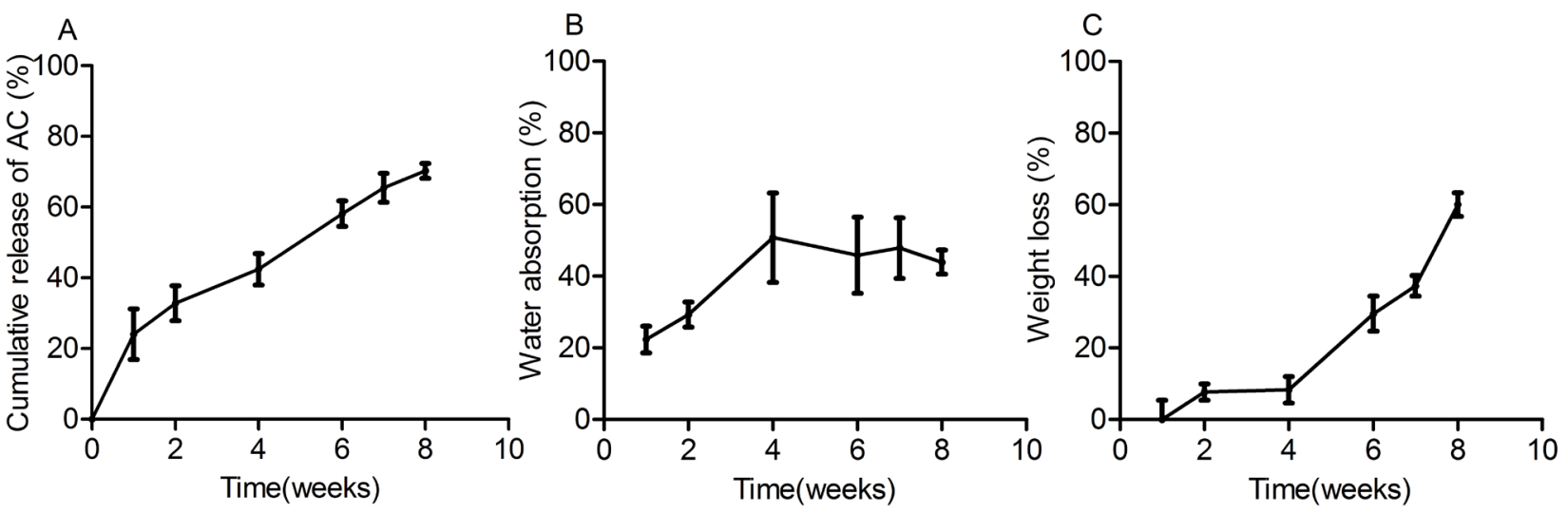

FIGURE 6 - In vitro release profile of CA from the polymeric device: (A) cumulative release of CA; (B) water absorption (C) weight loss. 


\section{In vivo antiangiogenic study}

Antiangiogenic activity of PLGA-CA devices was evaluated by CAM assay, which is a non-invasive, easy and a low-cost model (Kue et al., 2015). In this study, the antiangiogenic effect of CA was compared with that of bevacizumab, which is a well-known antiangiogenic drug used clinically. This drug is actually approved for the treatment of a few types of cancer, such as colorectal, lung and kidney. Furthermore, it is off-label used in the treatment of angiogenic pathologies of retina (Katrancioglu et al., 2012).

According to Figure 7, no statistical difference was observed between the groups treated with PBS and PLGA. Thus, the topical application of PLGA did not induce any decrease in vascularity. However, the treatment with CA-loaded PLGA implants was significantly different from the treatment with PLGA or PBS. CA-loaded PLGA implants lead to a reduction of approximately $17.5 \%$ in the vessels. A significant antiangiogenic effect was observed for membranes treated with CA suspension at $250 \mu \mathrm{g} \mathrm{mL}{ }^{1}$, which induced a reduction of $48.4 \%$ in the vessels. Bevacizumab at 250 $\mu \mathrm{g} \mathrm{mL} \mathrm{mL}^{-1}$ was used as a positive control and provoked an antiangiogenic effect of $50 \%$. No significant difference was found between bevacizumab at $250 \mu \mathrm{g} \mathrm{mL}^{-1}$ and CA suspension at $250 \mu \mathrm{g} \mathrm{mL}^{-1}$.

According to the in vitro study, considering that around $25 \%$ of CA content was released on the first week, we supposed that in 60 hours (time of implant contact with CAM), around $9 \%$ of CA $(12.5 \mu \mathrm{g})$ must be liberated. Hence, we expected that CA-loaded PLGA implants have led the same effect of CA $250 \mu \mathrm{g} \mathrm{mL} \mathrm{m}^{-1}$ suspension. However, this effect was not observed. In all likelihood, due to the hydrophobic structure of CA and consequently its higher affinity for the matrix, the burst event does not occur immediately, which means that more than 60 hours are required for this may happen. Therefore, even CA-loaded PLGA implants have reduced the vascularity, just CA suspension presented an antiangiogenic effect comparable with bevacizumab.

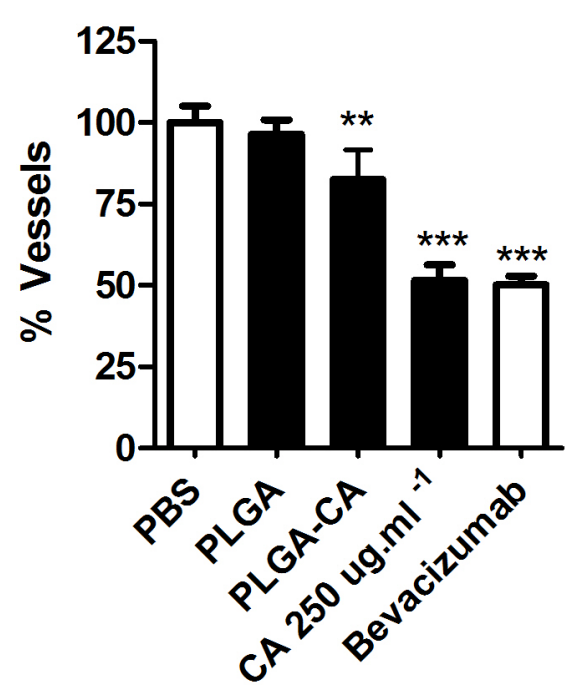

FIGURE 7 - CAM assay performed with PBS pH 7.4 (negative control), the blank implant of PLGA; CA-loaded PLGA implant; CA suspension at $250 \mu \mathrm{g} \mathrm{ml}^{-1}$ and bevacizumab $250 \mu \mathrm{g} \mathrm{ml}^{-1}$ (positive control). The negative control was fixed at $100 \%$. Results are expressed as mean $(\%) \pm \mathrm{SEM} ;{ }^{*} \mathrm{p}<0.05 ; * * \mathrm{p}<0.01 ; * * * \mathrm{p}<0.001$ compared to the negative control. 

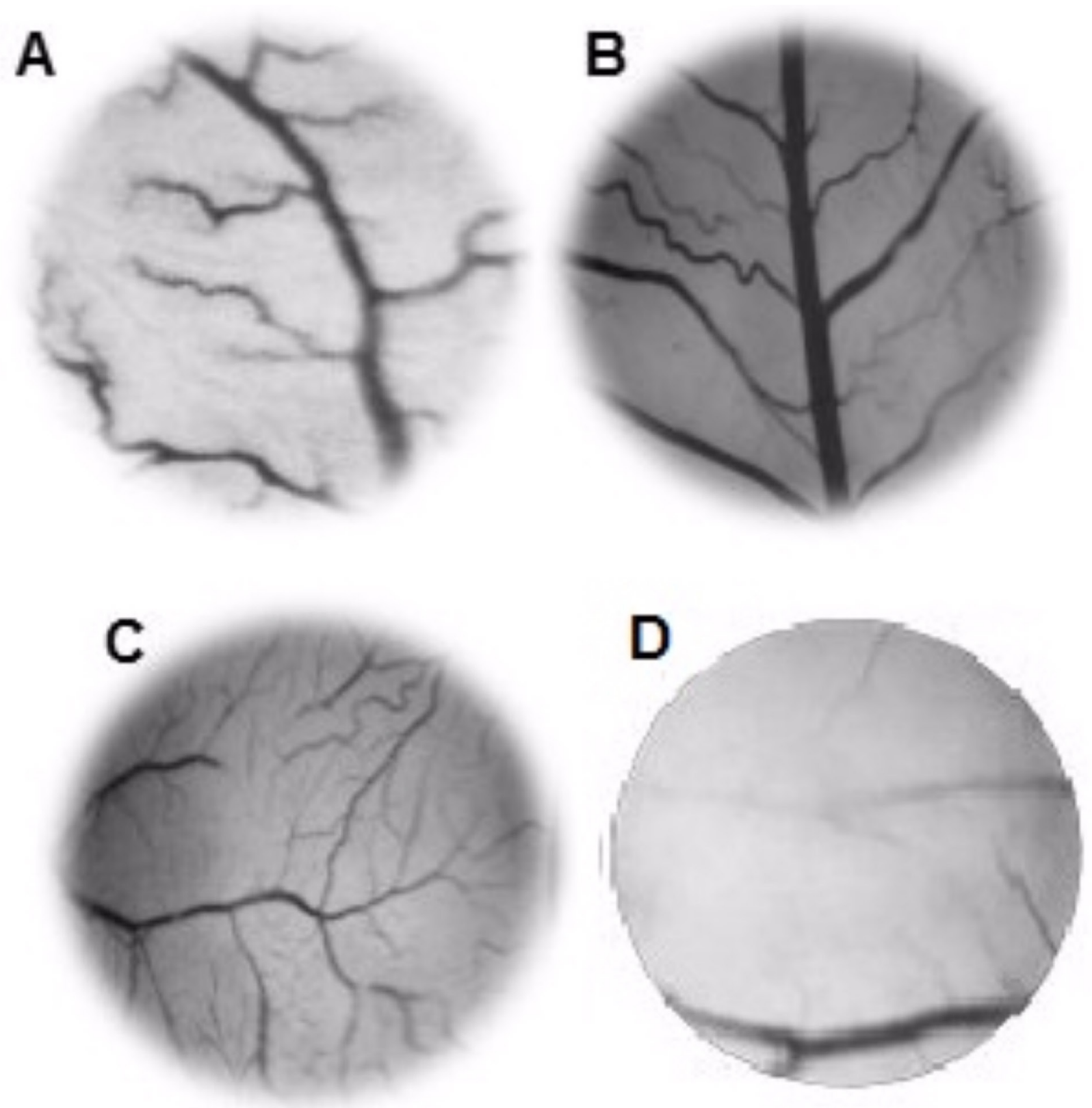

FIGURE 8 - Photographs of CAM treated with (A) PBS (B) blank implant (C) PLGA+AC implant (D) bevacizumab.

\section{CONCLUSION}

In this study, CA-loaded PLGA polymeric devices were successfully fabricated by the hot melt method and the drug showed to be dispersed uniformly in the matrix. The systems were physicochemical characterized by FTIR and DSC and no chemical interaction between the components of the formulation was verified. The in vitro release profile demonstrated that the PLGA-CA implants allowed a prolonged and controlled release of the triterpene, which was confirmed by SEM. In addition, the developed devices showed no toxicity and presented an antiangiogenic effect. Finally, this work provided a novel and interesting delivery system for CA, which presents as a promising therapeutic tool for the treatment of angiogenic pathologies. 


\section{CONFLICTS OF INTEREST}

The authors declare that they have no competing interests.

\section{ACKNOWLEDGMENTS}

The authors would like to thank Fapemig (Fundação de Amparo à Pesquisa do Estado de Minas Gerais), CNPq (Conselho Nacional de Desenvolvimento Científico e Tecnológico) and CAPES (Coordenação de Aperfeiçoamento de Pessoal de Nível Superior) for their financial support. We also thank NEPLAM (Núcleo de Estudo de Plantas Medicinais) of Chemistry Department of UFMG for the donation of corosolic acid.

\section{REFERENCES}

Alvarado HL, Abrego G, Garduño-Ramirez ML, Clares B, Calpena AC, García ML. Design and optimization of oleanolic/ursolic acid-loaded nanoplatforms for ocular antiinflammatory applications. Nanomed Nanotechnol Bio Med. 2015a;11(3):521-30.

Alvarado HL, Abrego G, Gardurno-Ramirez ML, Clares B, García ML, Calpena AC. Development and validation of a high-performance liquid chromatography method for the quantification of ursolic/oleanic acids mixture isolated from Plumeria obtusa. J Chromatogr B Anal Technol Biomed Life Sci. 2015b;983-984:111-6.

Anwer MK, Al-Mansoor MA, Jamil S, Al-Shdefat R, Ansari MN, Shakeel F. Development and evaluation of PLGA polymer based nanoparticles of quercetin. Int J Biol Macromol. 2016;92:213-9.

Arancibia-Radich J, Peña-Cerda M, Jara D, ValenzuelaBustamante P, Goity L, Valenzuela-Barra G, et al. Comparative study of anti-inflammatory activity and qualitative-quantitative composition of triterpenoids from ten genotypes of Ugni molinae. Bol Latinoam y del Caribe Plantas Med y Aromat. 2016;15(5):274-87.

Balakrishnan A, Al Assaf AH. Corosolic acid supresses the expression of inflammatory marker genes in CCL4-inducedhepatotoxic rats. J Pharm Sci. 2016;29(4):1133-7.

Behl T, Kotwani A. Possible role of endostatin in the antiangiogenic therapy of diabetic retinopathy. Life Sci. 2015;135:131-7.

Boimvaser S, Mariano RN, Turino LN, Vega JR. In vitro bulk/ surface erosion pattern of PLGA implant in physiological conditions: a study based on auxiliary microsphere systems. Polym Bull. 2016;73(1):209-27.

Cheng Q, Li H, Li Y, Liu Z, Guo X. CRA (Crosolic Acid) isolated from Actinidia valvata Dunn. Radix induces apoptosis of human gastric cancer cell line BGC823 in vitro via down-regulation of the NF-кB. Food Chem. 2017;105: 475-85.

Cossé A, König C, Lamprecht A, Wagner KG. Hot Melt extrusion for sustained protein release: matrix erosion and in vitro release of PLGA-based implants. AAPS PharmSciTech. 2017;18(1):15-26.

El-moghazy AM, Khalifa AA, Bayoumi SAL, Sayed H. Chemical constituents of ornamental pomegranate and its antioxidant and anti-inflammatory activities in comparison with edible pomegranate. J Pharmacogn Phytochem. 2016;5(4):88-94.

Eloy JO, Marchetti JM. Solid dispersions containing ursolic acid in Poloxamer 407 and PEG 6000: A comparative study of fusion and solvent methods. Powder Technol. 2014;253: 98-106.

Elshabrawy HA, Chen Z, Volin M V., Ravella S, Virupannavar S, Shahrara S. The pathogenic role of angiogenesis in rheumatoid arthritis. Angiogenesis. 2015;18(4):433-48.

Fialho SL, Silva-Cunha ADS. Drug delivery systems for the posterior segment of the eye: fundamental basis and applications. Arq Bras Oftalmol. 2007;70(1):173-9.

Gacche RN, Meshram RJ. Angiogenic factors as potential drug target: Efficacy and limitations of anti-angiogenic therapy. Biochim Biophys Acta Rev Cancer. 2014;1846(1): $161-79$.

Hussain K, Ismail Z, Sadikun A, Shah AMAM, Latif A, Hashmi FK. Antiangiogenic activity and bioassay-guided isolation of aqueous extract of orthosiphon stamineus. J Chinese Chem Soc. 2012;59(9):1137-43.

International Conference on Harmonisation. ICH Harmonised Tripartite Guideline Validation of Analytical Procedures: ICH Harmon Tripart Guidel Valid Anal Proced TEXT Methodol Q2(R1) step 4. 2005.

Jahangiri A, Davaran S, Fayyazi B, Tanhaei A, Payab S, Adibkia K. Application of electrospraying as a one-step method for the fabrication of triamcinolone acetonide-PLGA nanofibers and nanobeads. Colloids Surfaces B Biointerfaces. 2014;123:219-24.

Kanjoormana M, Kuttan G. Antiangiogenic activity of ursolic acid. Integr Cancer Ther. 2010;9(2):224-35. 
Kashyap D, Tuli HS, Garg VK, Bhatnagar S, Sharma AK. Ursolic acid and quercetin: promising anticancer phytochemicals with antimetastatic and antiangiogenic potential. Tumor Microenviron. 2018;1(1):9-15.

Katrancioglu N, Karahan O, Kilic AT, Altun A, Katrancioglu $\mathrm{O}$, Polat ZA. The antiangiogenic effects of levosimendan in a CAM assay. Microvasc Res. 2012;83(3):263-6.

Keles H, Naylor A, Clegg F, Sammon C. Studying the release of hGH from gamma-irradiated PLGA microparticles using ATR-FTIR imaging. Vib Spectrosc. 2014;71:76-84.

Ku CY, Wang YR, Lin HY, Lu SC, Lin JY. Corosolic acid inhibits hepatocellular carcinoma cell migration by targeting the VEGFR2/Src/FAK pathway. PLoS One. 2015;10(5):1-17.

Kue CS, Tan KY, Lam ML, Lee HB. Chick embryo chorioallantoic membrane (CAM): an alternative predictive model in acute toxicological studies for anti-cancer drugs. Esperimental Anim. 2015;64(2):129-38.

Li B, Meng X, Zhu L, Jiao X, Zhang J. Application of high-speed counter-current chromatography for isolation of triterpenes from schisandra chinensis (Turcz.) Baill and induction apoptosis mechanism of HSC-T6. Biomed Mater Eng. 2014;24(1):969-77.

Li Y, Zhou Z-H, Chen M-H, Yang J, Leng J, Cao G-S, et al. Inhibition of mitochondrial fission and NOX2 Expression prevent NLRP3 inflammasome activation in the endothelium: the role of corosolic acid action in the amelioration of endothelial dysfunction. Antioxid Redox Signal. 2016;24(16):893-908.

Lőrincz A, Mihály J, Németh C, Wacha A, Bóta A. Effects of ursolic acid on the structural and morphological behaviours of dipalmitoyl lecithin vesicles. Biochim Biophys Acta. 2015;1848(5):1092-8.

Ma P, Li T, Xing H, Wang S, Sun Y, Sheng X, et al. Local anesthetic effects of bupivacaine loaded lipid-polymer hybrid nanoparticles: In vitro and in vivo evaluation. Biomed Pharmacother. 2017;89:689-95.

Nazaruk J, Borzym-Kluczyk M. The role of triterpenes in the management of diabetes mellitus and its complications. Phytochem Rev. 2014;14(4)675-90.

Patel A, Cholkar K, Agrahari V, Mitra AK. Ocular drug delivery systems: an overview. World J Pharmacol. 2013;2(2):47-64.

Pereira VV, Silva RR, Duarte LP, Takahashi JA. Chemical constituents of Jacaranda oxyphylla and their acetylcholinesterase inhibitory and antimicrobial activities. Rec Nat Prod. 2016;10(3):392-6.

Soares DCF, de Paula Oliveira DC, Barcelos LS, Barbosa AS, Vieira LC, Townsend DM, et al. Antiangiogenic activity of PLGA-Lupeol implants for potential intravitreal applications. Biomed Pharmacother. 2017;92:394-402.

Solano AGR, de Fátima Pereira A, Pinto FCH, Ferreira LGR, de Oliveira Barbosa LA, Fialho SL, et al. Development and evaluation of sustained-release etoposide-loaded Poly(-Caprolactone) implants. Am Assoc Pharm Sci. 2013;14(2):890-900.

Sun S-B, Liu P, Shao F-M, Miao Q-L. Formulation and evaluation of PLGA nanoparticles loaded capecitabine for prostate cancer. Int J Clin Exp Med. 2015;8(10):19670-81.

Tan H, Sonam T, Shimizu K. The potential of triterpenoids from loquat leaves (Eriobotrya japonica) for prevention and treatment of skin disorder. Int J Mol Sci. 2017;18(5):1030.

Thakor P, Song W, Subramanian RB, Thakkar VR, Vesey DA, Gobe GC. Maslinic acid inhibits proliferation of renal cell carcinoma cell lines and suppresses angiogenesis of endothelial cells. J kidney Cancer VHL. 2017;4(1):16-24.

Vey E, Rodger C, Booth J, Claybourn M, Miller AF, Saiani A. Degradation kinetics of poly (lactic-co-glycolic) acid block copolymer cast fi lms in phosphate buffer solution as revealed by infrared and Raman spectroscopies. Polym Degrad Stab. 2011;96(10):1882-9.

Yang J, Leng J, Li JJ, Tang JF, Li Y, Liu BL, et al. Corosolic acid inhibits adipose tissue inflammation and ameliorates insulin resistance via AMPK activation in high-fat fed mice. Phytomedicine. 2016;23(2):181-90.

Yasukawa T, Ogura Y, Sakurai E, Tabata Y, Kimura H. Intraocular sustained drug delivery using implantable polymeric devices. Adv Drug Deliv Rev. 2005;57(14 Spec. Iss.):2033-46.

Yoo KH, Park J-H, Lee DY, Hwang-Bo J, Baek NI, Chung IS. Corosolic acid exhibits anti-angiogenic and antilymphangiogenic effects on in vitro endothelial cells and on an in vivo CT-26 Colon carcinoma animal model. Phyther Res. 2015;29(5):714-23.

Zhu WJ, Yu DH, Zhao M, Lin MG, Lu Q, Wang QW, et al. Antiangiogenic triterpenes isolated from chinese herbal medicine Actinidia chinensis Planch. Anticancer Agents Med Icinal Chem. 2013;13(2):195-8.

Received for publication on $22^{\text {nd }}$ June 2018 Accepted for publication on $07^{\text {th }}$ January 2019 